\title{
A força poética na memória dos objetos
}

The poetic power in the memory of objects

Sandra Vargas $^{1}$ 


\section{Resumo}

O presente artigo discute o uso do Teatro de Objetos, destacando primeiramente o conceito, que pautou os seus criadores, que é o uso simbólico dos objetos. Relata experiências do Sobrevento a partir do uso dos objetos em relação à memória que eles carregam. Descreve a experiência da construção de um Museu-Teatro, a partir de objetos com histórias dos vizinhos do Teatro do Sobrevento, assim como apresenta os espetáculos que resultaram desta busca que o grupo vem trilhando ao longo dos anos.

Palavras-Chave: Objetos; memória; teatro

\section{Abstract}

This article discusses the use of the Object Theatre, initially highlighting the concept that guided its creators, which is the symbolic use of objects. It reports Sobrevento experiences on the use of objects regarding the memory they carry within. It describes the experience of setting up a Theater-Museum of Objects representing the stories of the Sobrevento Theater neighborhood as well as it presents the performances that resulted from this search that the group has been treading over the years.

Keywords: Objects; memory; theater

ISSN: 1414.5731

E-ISSN: 2358.6958

1 Atriz, diretora teatral e curadora de festivais de teatro. Uma das fundadoras do Grupo Sobrevento (Rio de Janeiro, 1986), grupo que se dedica à prática do teatro de animação em suas diferentes formas de expressão. O Grupo hoje atua em São Paulo. E-mail: grupo@sobrevento.com.br 
A primeira vez que ouvi falar em Teatro de Objetos foi o marionetista francês Philippe Genty, quando tivemos a sorte de que três integrantes do nosso Grupo, o Sobrevento, fossem selecionados, junto com outros jovens marionetistas da América Latina, para fazer um curso com ele, por um mês, na cidade de Trujillo, no Peru, em 1988. Naquele curso, um dos módulos era o Teatro de Objetos, apresentado como uma vertente do Teatro de Animação, no qual se definiam algumas de suas particularidades e características, e realizavam-se experimentos. Aquilo, para nós, foi uma surpresa, pois Genty nos falava em um Teatro de Bonecos sem bonecos, com objetos prontos (ready-mades), em que a manipulação, com todos os seus princípios (direção do olhar, ponto fixo, dissociação, eixo e nível), era muito discreta, não sendo, definitivamente, o mais importante.

No dia 2 de março de 1980, três companhias de Teatro de Animação (Théâtre de Cuisine - Katy Deville e Christian Carrignon -, Vélo Théâtre - Tania Castaing e Charlot Lemoine - e Théâtre Manarf - Jacques Templeraud) assistem ao espetáculo do húngaro Gyula Molnár, Pequenos Sucídios, no qual vemos um trágico e anunciado suicídio de um Alka-Seltzer em um copo de água, diante da rejeição sofrida por um punhado de bombons (da marca Garoto, diga-se de passagem); o amor de Jörg, jovem sueco, um fósforo, que se consome de amor por Pita, brasileira, fascinante e encantadora, um grão de café; e uma alegoria sobre o tempo, por meio da história do relacionamento do autor com sua tia excêntrica, entre amendoins, carteira, cédulas, mapa, fotos $3 \times 4$. Estes trabalhos apresentavam uma forma de fazer teatro que as três companhias acreditavam assemelhar-se com o teatro que vinham fazendo e que percebiam ser diferentes dos espetáculos de Teatro de Bonecos. Foi Katy Deville - fundadora do Théâtre de Cuisine, junto com Christian Carrignon - que, naquela madrugada, após assitir a Gyula Molnár, mencionou pela primeira vez o termo Teatro de Objetos.

Christian Carrignon e Katy Deville integraram a Companhia de Philippe Genty e já apresentavam os seus espetáculos: Vinte Minutos Sob o Mar e Théâtre de Cuisine. Genty assistiu a esses trabalhos e percebeu a diferença desta linguagem com o Teatro de Animação. Genty não trabalhava com Teatro de Objetos, mas deu-se conta da importância daquele movimento que começava a se fortalecer e passou a difundir os princípios do Teatro de Objetos, tal qual os percebia, a partir do trabalho daqueles artistas, ainda que suas próprias criações seguissem outros rumos.

Desde 2009, venho estabelecendo contato com artistas e companhias internacionais de Teatro de Objetos, por ocasião da realização de 12 edições do Festival Internacional de Teatro de Objetos (FITO) - que aconteceram em diferentes cidades do Brasil -, na qualidade de curadora do evento, de cinco edições da Semana Internacional de Teatro de Animação do Sobrevento, além de quatro Residências Internacionais de Teatro de Objetos, realizadas em São Paulo, na sede do Sobrevento, ambas na qualidade de diretora artística, junto com Luiz André Cherubini, do Grupo Sobrevento. ${ }^{2}$ Tivemos a oportunidade de trazer ao Brasil importantes expoentes deste gênero, tais como: Katy Deville e Christian Carrignon (Théâtre de Cuisine, França); Jaime Santos (Companhia Chana Teatro, Espanha) e que também foi aluno de Philippe Genty); Agnés Limbós (Gare Central, Bélgica); Roland Shon (Théâtre en Ciel, França); 
Antônio Catalano (La Cassa Degli Alfieri, Itália); Hermanos Oligor (Espanha) e Xavier Bobès (Espanha). Destaco estes, entre as mais de 60 companhias que conseguimos trazer ao país, pois eles, além de terem apresentado os seus espetáculos, ministraram oficinas ou fizeram residências artísticas. Graças a isso, pude constatar que a grande maioria das companhias hoje atuantes no campo do Teatro de Objetos, ainda se pautam por aqueles mesmos princípios que Philippe Genty percebeu nos primórdios do movimento, e que buscou difundir nos muitos cursos que ele tem ministrado em diferentes países.

Considerando esses princípios, Genty define o Teatro de Objetos como uma vertente do Teatro de Animação que se vale de objetos prontos, no lugar de bonecos, deslocando-os da sua função e conferindo-lhes novos significados, sem transformar, porém, a sua natureza, explorando uma dramaturgia que se vale da linguagem simbólica, em detrimento da importância da manipulação propriamente dita. Dentro deste conceito, portanto, tentar fazer um boneco, forçando a ilusão de um movimento humano a partir da junção de diferentes objetos, ou colocando dois olhos em um objeto, não constituiria um Teatro de Objetos, mas um Teatro de Bonecos feito de objetos.

Observamos, então, que, para trabalhar a linguagem do Teatro de Objetos, o primeiro aspecto é pensar em como podemos dar novas funções aos objetos, sem transformar a sua natureza. Quando falo da natureza do objeto, me refiro à ideia de que todos sabemos para que serve aquele objeto e qual é a sua função, e, considerando o que o espectador sabe dele, é que nos valeremos da linguagem simbólica, para dar uma outra função a esse objeto, de preferência, uma função poética. Neste caso, a linguagem simbólica é usada, tal qual na poesia escrita, isto é, entendida como associações de ideias, que operam pela metáfora, que é quando se emprega um termo com significado diferente do habitual, com base numa relação de similaridade entre o sentido próprio e o sentido figurado.

Por exemplo:

Relógio = Tempo;

Ampulheta = O tempo preso;

Binóculos = Invasão à privacidade.

Trata-se de fazer um jogo de ressignificar o objeto, baseado naquilo que o espectador sabe do objeto. Assim, vemos que não podemos escolher qualquer objeto para expressar a personagem ou ideia que buscamos: o objeto escolhido deve criar no espectador uma associação metafórica que o transforme em outra coisa além do que ele é, sem que deixe de ser o que ele efetivamente é. Precisaremos, portanto, encontrar em um objeto algo que justifique associá-lo à ideia ou à imagem que escolhemos.

É importante destacar, que para poder fazer esse jogo, sempre devemos trabalhar com objetos que sejam fáceis de reconhecer por todos. Agnés Limbós, da Companhia Gare Central, da Bélgica, um dos maiores nomes desta linguagem no mundo, afirma que Teatro de Objetos sempre deve ser trabalhado com objetos manufaturados, justamente para que a metáfora funcione, pois todos reconhecerão o objeto. Quando não se reconhece o objeto é impossível fazer a metáfora.

O mais provocador do Teatro de Objetos, no entanto, para nós do Grupo Sobrevento, não está no conceito mas em como, por meio dessa linguagem, revelamos o 
que há de mais profundo dentro de nós. Teatro de Objetos é autobiográfico: mesmo quando não queremos, os objetos impõem uma tomada de posições e nos fazem revelar o nosso olhar da realidade que nos cerca.

Por exemplo, em relação a um maço de cigarros, podemos observar como a escolha de diferentes metáforas, para um mesmo objeto, revela diferentes pontos de vista de quem faz a metáfora e, portanto, revela um pouco de quem ele é.

Maço de cigarros = Morte.

Maço de cigarros = Prazer.

Indo mais fundo, pensemos no clássico Pequenos Suicídios. Gyula Molnár é húngaro e criou esse espetáculo quando foi morar na Itália. Pequenos Suicídios fala do sentimento de um imigrante. No espetáculo, um Sonrisal tenta se misturar a um punhado de bombons "Garoto", e num momento o ator que está por trás come um bombom e joga fora o papel que embrulhava o bombom. Ele abre o Sonrisal e o envolve no papel do bombom, e por um momento o Sonrisal, "disfarçado de bombom", mistura-se aos outros, mas é descoberto. O ator pega o Sonrisal e o joga no copo de água. Aqui, o ator é o Sonrisal, é o imigrante, é o estranho, é aquele que tenta se misturar e não consegue, e é o suicida. Os diretores Christian Carrignon e Jean-Luc Mattéoli (2006, p. 7) afirmam:

O Teatro de Objetos pertence ao nosso tempo e à nossa sociedade. É um Teatro que nasce no fim do século XX, em um mundo invadido por objetos made in China. Qualquer que seja a história que conte, o Teatro de Objetos fala sobre nós, por meio das coisas manufaturadas reconhecíveis por todos. O Teatro de Objetos fala das pequenas coisas cotidianas. Cada espectador tem uma lembrança pessoal ligada a um certo objeto.

Ao que acrescenta: "A vocação primeira do Teatro de Objetos é a de tocar nossa intimidade, de interrogar o enigma que nós somos aos olhos dos outros" (Idem).

No Sobrevento, pouco a pouco pudemos nos aprofundar nos princípios e nos conceitos dessa linguagem, graças ao contato com as tantas companhias com as quais promovemos importantes intercâmbios internacionais, que conseguimos realizar graças às subvenções dadas à nossa companhia mediante a Lei de Fomento ao Teatro da cidade de São Paulo.

Nesta pesquisa temos seguido dois caminhos: o da escolha da utilização do objeto de forma simbólica, como construção de metáforas poéticas; e também o de buscar a poesia dos objetos a partir das memórias que eles disparam no ator. Neste último caso, o ator aqui não seria nem manipulador nem personagem. Um estudo realizado na Universidade Nacional da Colômbia afirma:

Os objetos que dão sentido a um lugar, e com uma carga afetiva adquirem outro status desde a ordem simbólica, se convertem em autobiografias e testemunho de lugares vividos e de enunciação da memória, isto é, os objetos acabam por ser representações da história pessoal e veículos para voltar a ver e a percorrer o território. São a bússola e o guia de regresso para encontrar o caminho que nos leva ao que já vivemos. (Ruiz, 2003, p. 61)

Manipular um objeto e fazer dele um boneco não faz nenhum sentido para nós, pois ainda estaríamos fazendo Teatro de Animação. O objeto já tem muita vida 
naquilo a que ele nos remete, portanto, dar vida a esse objeto é revelar a história que ele porta. Percebemos que o Teatro de Objetos pode contribuir para trilhar outros caminhos de dramaturgia quando investigamos a história que ele traz. Para Leonardo Boff $(1996$, p. 3):

Quem não possui um objeto em casa, que é para si memória de um acontecimento, sinal de uma amizade, testemunho de uma história, de uma relação? Ao olhar frio de quem o vê para lá da aparência o objeto é igual a cem mil objetos. Mas ao olhar daquele que o possui ele é evocativo de uma história, de uma amizade.

Nas palavras de Boff, o objeto deixa de ser um objeto igual a cem outros quando a lembrança da história que ele carrega é revelada. É dessa forma que daremos uma outra função ao objeto, que já não será somente o objeto puro, mas, também, a lembrança que ele carrega.

Desde 2012 vimos ministrando Oficinas de Teatro de Objetos, e nelas, para ter um material que propiciasse uma dramaturgia poeticamente potente, pedíamos aos participantes para que nos trouxessem objetos que remetessem a uma lembrança boa e a uma lembrança ruim. Foram muitas oficinas e por isso ouvimos muitas histórias escondidas nos objetos, que não terminavam de nos surpreender. A partir disso começou a nos perseguir a ideia de trabalhar com a memória escondida nos objetos. Decidimos, então, neste projeto, criar um museu com as histórias dos objetos dos vizinhos do bairro do nosso teatro. Descobrimos que algumas companhias também estavam interessadas em explorar este aspecto dos objetos.

Nós convidamos duas delas a virem a São Paulo e compartilhar essa experiência conosco: o Théâtre de Cuisine e o Théâtre en Ciel, da França.

Da Cia. Théâtre de Cuisine, vieram Katy Deville e Christian Carrignon, pois os dois já estão há alguns anos trabalhando com oficinas de formação cujo resultado final é a construção de um museu. O museu ainda está muito ligado ao conceito da metáfora associada diretamente ao objeto, independente da memória ou história do objeto. Eles pedem aos alunos para trazerem muitos objetos e colocam o desafio de associar um provérbio ao objeto, e em cada objeto é colocada uma etiqueta com um provérbio. Eles colocam uma condição: todas as frases devem começar assim: "O meu avô era...".

Por exemplo: Num porta-joia, alguém amarrou uma etiqueta que dizia: "O Meu avô era uma joia rara".

Roland Shön, do Théâtre en Ciel, foi também convidado, pois soubemos que havia alguns anos desenvolveu um projeto que consistia em coletar histórias pessoais por meio dos objetos. O seu projeto consistia em marcar um encontro com uma pessoa da sua cidade, podia ser num café, numa biblioteca ou num teatro, e essa pessoa trazia um objeto e lhe contava a história do objeto; depois ele perguntava se podia gravar, e todos aceitavam. Ele gravava enquadrando somente os objetos e as mãos do dono da história, e dessa forma a pessoa se mantinha anônima. Muitas vezes, quem decidia como enquadrar, o plano de fundo, se seria numa mesa, com um pano ou não, era o próprio dono da história, que ficava muito à vontade para dirigir a gravação. Shön recolheu cerca de 300 histórias. Depois teve a ideia de fazer um museu, onde havia um corredor, formado entre a parede e um tecido que era colocado afastado. A cada 
certa quantidade de metros, havia uma abertura no tecido, pequena e retangular, com uma tábua que funcionava como suporte, para colocar os objetos. As pessoas entravam naquele corredor, com os seus objetos, e contavam a história do seu objeto, nas aberturas. As pessoas, que estavam do lado de fora do corredor, paravam para ouvir a história sem ver quem era a pessoa que contava a história.

A ideia de Roland Shön é muito diferente daquela do Théâtre de Cuisine, pois Roland Shön trabalha com a história verdadeira de cada objeto. Posso dizer que o Museu do Théâtre de Cuisine desperta no público uma sensação mais distante, há mais curiosidade do que emoção, ao contrário do que acontece com o Museu de Objetos criado a partir de memórias.

Aqui em São Paulo, fizemos o nosso Museu - Teatro da Vizinhança, com a colaboração de ambas as companhias. Coletamos histórias e objetos junto à nossa vizinhança, fazendo com que cada ator saísse a campo. As histórias foram reescritas a partir do que cada um ouviu. Expusemos os objetos no nosso galpão e penduramos, ao lado de cada objeto, numa moldura, a história escrita e narrada pelos nossos vizinhos. Durante a abertura do museu, os vizinhos podiam sentar ao lado de cada um dos seus objetos e, se quisessem, eles mesmos podiam contar a sua história pessoalmente, resultando num Museu-Teatro. Foi uma experiência muito rica: o teatro, para nós, estava no encontro, estava no ouvir os vizinhos, estava no laço afetivo que criamos com a vizinhança.

Da relação do objeto com a memória, o Sobrevento, criou alguns espetáculos, tais como: Eu Tenho uma História (2012) Sala de Estar (2014) Terra e Escombros (2017).

Em Eu Tenho uma História, buscamos misturar a história dos bairros Brás e Belenzinho, lugares tradicionais de São Paulo, ao Teatro de Objetos. O Sobrevento queria falar de sua vizinhança e buscar um teatro fora de uma sala de espetáculos. Partindo da estrutura de "estações cênicas", chegou à construção de pequenas tendas circulares, levadas a espaços abertos, como parques e praças. Em quatro barracas, uma história do entorno da sede do Espaço Sobrevento - o seu Teatro. Por meio de objetos, o Sobrevento fala de figuras ilustres - como Luís Gama, Ricardo Mendes Gonçalves e Francisco Alves -, que tiveram suas vidas vinculadas à região e também dos trabalhadores que ajudaram a construir o bairro, cujas profissões estão em vias de desaparecer. No espetáculo, um cuidado que tivemos foi o de relacionar os personagens dos narradores a seus objetos e histórias, sempre de forma surpreendente: é uma costureira boliviana (muitos bolivianos têm uma vida de escravos, na cidade de São Paulo) quem conta, com botões, a história de Luís Gama, que foi escravo, embora tivesse nascido livre, e que se tornou um advogado abolicionista; é um homem em meio a muitas flores que conta a história do poeta dos ipês; uma moça japonesa é quem conta a história das cristalerias italianas do Belenzinho, com cristais da única cristaleria que ainda fica no bairro e resiste para não desaparecer; e por último é um boêmio em uma mesa de bar quem conta o último show de Francisco Alves, no Largo da Concórdia, no Brás. Cada cena dura de 10 a 15 minutos. Em cada tenda podem entrar até 15 pessoas, tentando preservar a relação íntima de que o Teatro de Objetos precisa. As sessões podem acontecer seguida e simultaneamente, durante uma hora aproximadamente, de acordo com o público presente. Ao fim de cada apresentação, os atores colam etiquetas nos espectadores, com os dizeres "EU TENHO UMA HISTÓ- 
RIA". A ideia é lembrar que o Brás tem uma história, que tem muitas histórias, que cada um de nós tem histórias, igualmente bonitas e importantes. Essa mesma intervenção podemos levar a outra cidade ou bairro, resgatando a história de cada lugar. O bonito das apresentações, é ver a emoção de cada morador do lugar, que se sente valorizado por trazer a história do seu lugar. Em muitas ocasiões vimos vizinhos ficarem na tenda, após as apresentações, lembrando de outras histórias do bairro, gerando uma conversa entre eles da qual o ator não fazia parte e a ele só cabia observar e escutar.

Sala de Estar nasce do cruzamento de segredos dos atores, escondidos em coisas que deveriam revelar a fragilidade de cada um de nós. Os objetos foram usados como suporte de memórias poéticas e eles estão presentes no que é dito por meio deles, eles estão presentes no segredo dito de cada um. Ao fim, chegou-se a um espetáculo itinerante, composto de seis estações cênicas, nas quais são apresentadas histórias que se assemelham a confissões de cada ator. Cada cena revela, com delicadeza e singeleza, as lembranças e os segredos - nem sempre verdadeiros - adormecidos em suas memórias. Para o desenvolvimento da ideia, os atores se valeram de objetos bem diferentes - gaveteiro, escrivaninha, sofá, chapeleiro, fotografias e cartas -, e por todos os objetos se tratarem de coisas de casa, explorou-se a ideia de que os atores estariam num ambiente que remetesse a uma Sala de Estar, e em cada sala os atores usariam figurinos que os fizessem parecer estar encrustados em suas salas de estar, como mais um móvel do ambiente.

Numa sala vemos uma mulher sentada num sofá, com pele de onça: ela está vestida com um terno de pele de onça, os pés do sofá são patas de um leão. A cena segue a linha do absurdo, no qual a atriz culpa o sofá por todas as catástrofes da humanidade. Na cena, a atriz vai delirando e dizendo o quanto é inútil um sofá. Durante toda a cena, o público ri, dos argumentos absurdos, dos quais a atriz se vale para demonstrar o seu ódio aos sofás: por serem os responsáveis pelas enchentes, pois sempre vemos sofás jogados nas ruas e, quando chove, são os primeiros a serem arrastados pelas águas, entupindo os bueiros; o ridículo dos sofás de três lugares, que não servem para conversar, principalmente quando a pessoa senta no meio; e assim inúmeros argumentos plenos de contrassenso que criam um clima absurdo para depois ser revelado o ódio àquele objeto, porque seria num móvel desses em que, na infância, teria acontecido uma cena de abuso.

Noutra sala vemos uma mulher ler cartas: são cartas que estão fora de ordem, e o espectador vai se envolvendo, na tentativa de compreender a situação. As cartas são de uma mãe que foge da ditadura militar, nos anos de 1970 , no Chile. No fim o espectador compreende que a filha é a própria atriz que lê as cartas.

São seis estações, em que o espectador entra na intimidade de cada pessoa daquelas salas, mas a força de Sala de Estar não está no segredo de cada ator, e sim no cruzamento com os objetos e no tipo de relação que é proposta ao espectador. O ator ali não é personagem, mas também não é ele mesmo. Ele vive uma situação junto com o espectador. Nessa peça, o Teatro de Objetos, ligado à memória, nos faz tirar o ar espetacular ao teatro, no qual o trabalho do ator está entre a presença real e poética perante o espectador.

Terra tem por mote os objetos e a memória que todo ser humano, até mesmo o bebê. Memórias guardadas, enterradas, desenterradas, escondidas, reveladas, dançam 
em um círculo de terra escura e úmida que abriga uma única atriz em cena. Inspirada pelo costume que muitas crianças têm de enterrar coisas que lhes são significativas, criou-se um texto que fala de memória, dos laços afetivos e do amor que está dentro de todos nós e que está debaixo da terra. Os objetos, nesse espetáculo, entram como representação de cada ente querido que a atriz desenterra das suas memórias. Sobre a terra - ora um jardim, ora um leito, ora um mar - suspende-se um céu de estrelas, que ela monta a partir de um livro, do seu livro. Nesse espetáculo é muito forte para o espectador o fato de desenterrar objetos da terra; acreditamos que a força está no objeto puro, não são desenterrados objetos adereçados, vemos objetos como: um vidro de perfume, cacos de prato de louça, um pano de rendinha, uma colher e um livro - todos os objetos parecem ter história e por isso ganham em força poética.

Em Escombros, parte-se da mesma busca da relação entre objetos e memórias do espetáculo anterior, mas chega-se a um espetáculo, dessa vez, para adultos. Escombros trata da destruição, da ruína de pessoas, de relacionamentos, de valores, de um país e do mundo. Pessoas que perderam tudo, vagam sobre escombros e tentam, apesar de toda a desesperança que paira no ar, compreender como tudo se perdeu sem que se dessem conta, e tentam recompor um mundo que desabou e já não existe mais. Entre as ruínas de uma casa, objetos como portas, janelas, cadeiras, mesas, uma penteadeira e muitas xícaras e bules de café falam do desabamento de um país, e de tudo o que foi demolido com ele ou que o fez desmoronar. Cenas muito simples e cotidianas, diálogos desamarrados, coreografias segmentadas revelam o vazio e a desconexão das figuras que transitam sobre uma ausência de memórias e perspectivas. Os objetos são usados em tamanho natural, ao contrário das miniaturas que abundaram no Teatro de Objetos. Entre os tantos quadros, cito um no qual vemos um homem carregar uma porta e colocá-la em pé, no meio da cena, e logo entra uma mulher que bate à porta desesperadamente, pedindo para abrir e deixá-la entrar; ele diz que não e que o lugar dela não é ali. Ela implora, empurra e, quando já não tem mais forças, desiste e sai. Quando ela vai embora, o homem derruba a porta no chão. A metáfora aqui se dá na situação, na porta que não se abre, num mundo em que cada vez mais há menos portas que se abrem para o outro.

Escombros e Terra fizeram parte de um projeto em que nos debruçamos sobre a questão memória: memória como um material poético a ser cruzado com os objetos, memória do nosso grupo, que completava 30 anos, memória do bairro onde fica o nosso teatro.

No Teatro de Objetos é necessário afinar uma escuta para não impor histórias a ele e repetir fórmulas e formas de fazer teatro. Percebemos que o Teatro de Objetos ligado à memória nos levou a fazer um outro teatro, a estabelecer uma outra forma de comunicação com o público, mais delicada, mais visceral e mais frágil. Para isso tivemos de nos despir, aprender a ouvir o objeto, a investigar, com respeito e delicadeza, a história que ele carrega, pois há um exercício de exposição que deve ser tratado com muito cuidado e deve fazer sentido para a poesia e a forma de expressão que buscamos. A poética não está somente no depoimento ou na história que ouvimos do objeto, mas no tratamento que damos a ele no teatro e no quanto ele nos transforma como artistas. 


\section{Referências}

BOFF, Leonardo. Os Sacramentos da Vida e a Vida dos Sacramentos - Trabalho de Curso de Formação de Catequeses do Colégio São Gonçalo. São Gonçalo: mimeografado, 1996.

CARRIGNON, Christian; MATTÉOLI, Jean-Luc. Le théâtre d'objet: mode d'emploi. Dijon: Ed. Scèrén/CRDP de Bourgogne, 2006.

RUIZ, Marta Isabel Arroyave. Objetos de la memória en el destierro. Medelin Universidad Nacional de Colombia. Tesis. 2003.

Recebido em: $11 / 08 / 2018$

Aprovado em: 11/08/2018 